\title{
TORSION TESTING OF DIFFUSION BONDED LIGA FORMED NICKEL
}

T.R. Christenson, T.E. Buchheit, and D.T. Schmale

Sandia National Laboratories, PO Box 5800, MS-0329, Albuquerque, NM 87185

\section{ABSTRACT}

A test technique has been devised which is suitable for the testing of the bond strength of batch diffusion bonded LIGA or DXRL defined structures. The method uses a torsion tester constructed with the aid of LIGA fabrication and distributed torsion specimens which also make use of the high aspect ratio nature of DXRL based processing. Measurements reveal achieved bond stengths of $130 \mathrm{MPa}$ between electroplated nickel with a bond temperature of $450^{\circ} \mathrm{C}$ at 7 ksi pressure which is a sufficiently low temperature to avoid mechanical strength degradation.

\section{INTRODUCTION}

Extending planar processing techniques used in micromechanical device fabrication to allow greater structural thicknesses has been an ongoing ambition of both high aspect-ratio silicon etching technology [1] and additive high aspect-ratio metal microfabrication [2,3]. Upon achieving precision high aspect-ratio structures, implementing subsequent layers or patterns becomes an additional challenge with the desire to maintain the microlithographic precision between the additional layers. This requirement is found to immediately lead to the necessity of planar substrates and planarized structural layers with well controlled thickness. In LIGA [3] or deep x-ray lithography (DXRL) based processing this planarization requirement has been satisfied using precision diamond lapping techniques which are used to restore planarity to the non-uniform electroformed layer[4]. The result is control of the thickness or $z$-dimension to a degree near that of the $x-y$ prismatic part definition.

The next step in fabrication evolution is to accommodate additional layers for increased three-dimensionality. This has been accomplished for two levels by successive electroforming steps on the same substrate [5]. A more general approach makes direct use of the flat precision lapped and polished surfaces via a diffusion bonding technique [6]. This approach has recently been applied to the batch fabrication of multi-level mechanical LIGA structures. The process sequence in cross section is shown in Fig. 1. Two substrates decorated with DXRL defined electroformed and planarized geometry are mated via a precision alignment

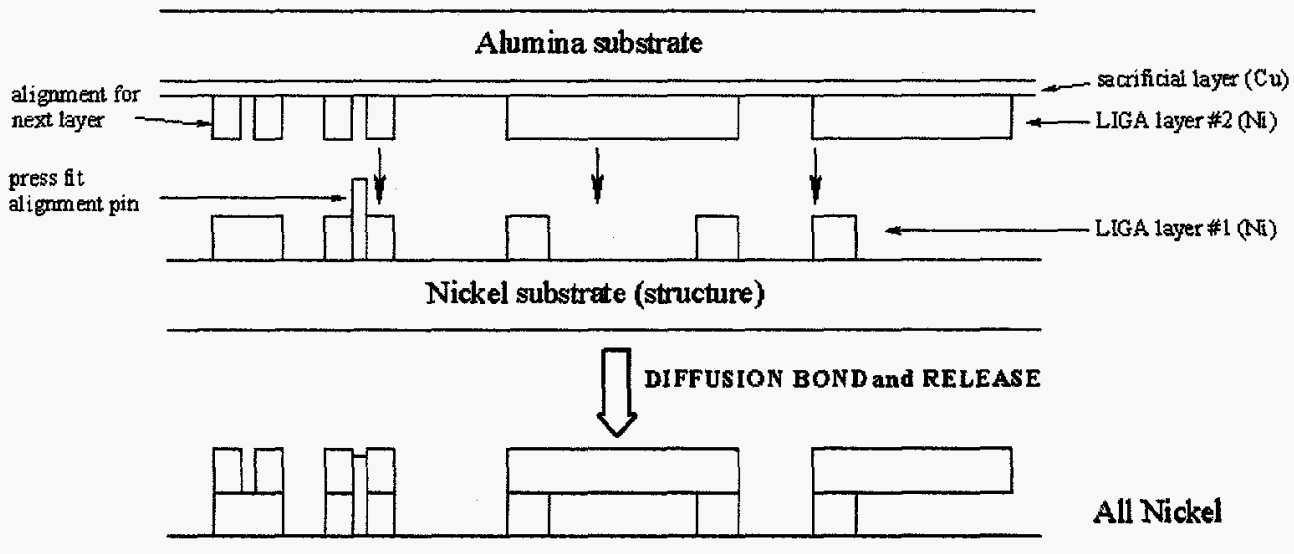

Fig. 1 Diffusion bonding process applied to the batch fabrication of multi-level LIGA structures. 


\section{DISCLAIMER}

This report was prepared as an account of work sponsored by an agency of the United States Government. Neither the United States Government nor any agency thereof, nor any of their employees, make any warranty, express or implied, or assumes any legal liability or responsibility for the accuracy, completeness, or usefulness of any information, apparatus, product, or process disclosed, or represents that its use would not infringe privately owned rights. Reference herein to any specific commercial product, process, or service by trade name, trademark, manufacturer, or otherwise does not necessarily constitute or imply its endorsement, recommendation, or favoring by the United States Government or any agency thereof. The views and opinions of authors expressed herein do not necessarily state or reflect those of the United States Government or any agency thereof. 


\section{DISCLAIMER}

Portions of this document may be illegible in electronic image products. Images are produced from the best available original document. 
scheme using press-fit gauge pins. The two metal substrates are then placed in a vacuum hot press for diffusion bonding after which they are placed in an etchant that entirely removes the sacrificial substrate in preparation for additional layers. The gauge pins with diametrical tolerance of $+1 \mu \mathrm{m} /-0 \mu \mathrm{m}$ ensure submicron interlayer alignment tolerance as shown in the test structures of Fig. 2. Figure 3 shows examples of resulting two-level structures. This technique is seen to be able to accommodate any number of levels and thus forms the basis for a multiple level process which may include interleaved sacrificial layers to allow eventual batch release of movable mechanisms.

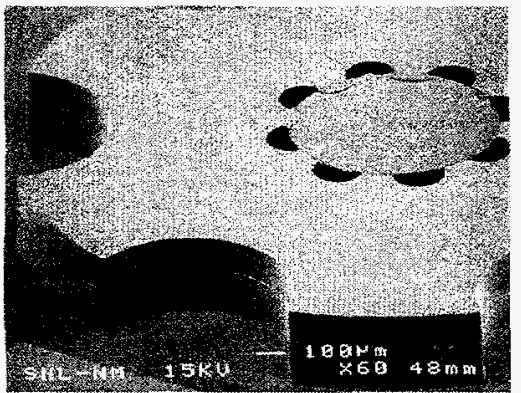

(a)

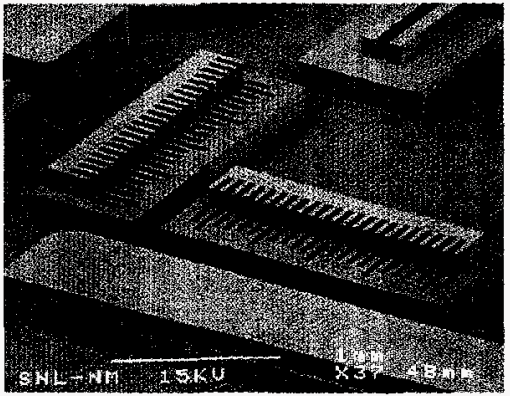

(b)

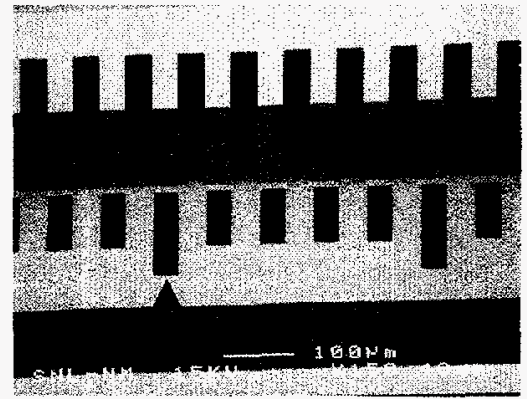

(c)

Fig. 2 Press-fit gauge pin alignment results showing: (a) 32.0 mil diameter gauge pin press-fit into alignment structure after $2^{\text {nd }}$ layer release, (b) $\mathrm{x}$ and y alignment verniers resulting from 2 layer bonding and (c) close-up of alignment verniers indicating submicron alignment (each vernier marker corresponds to $0.5 \mu \mathrm{m}$ misalignment.

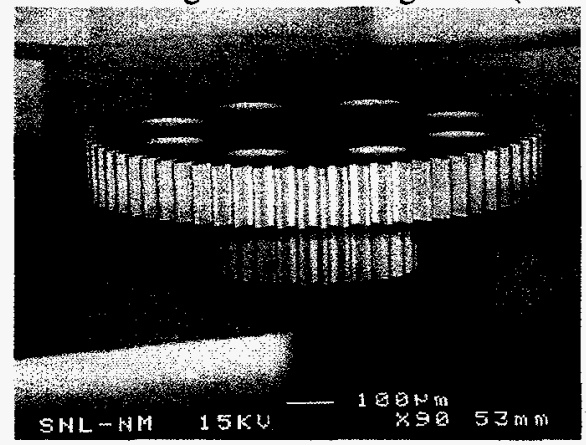

(a)

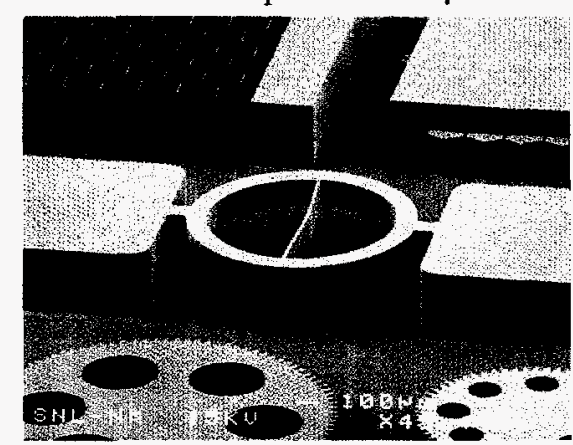

(b)

Fig. 3 Examples of 2-layer diffusion bonded structures of interest. (a) large gear on small gear (backscatter image) (b) ring and beam structure indicating tensile stress in LIGA layer 2.

Ideally, the diffusion bond should take place at the lowest temperature possible with a minimum amount of pressure. This stipulation is particularly important when it is recognized that the mechanical strength and hardness of commonly LIGA electroformed materials degrades with high temperature treatments due to grain growth. A method to characterize bond strength as a function of diffusion bonding parameters utilizing specimens commensurate with the LIGA diffusion bonding technique is therefore needed. This paper discusses a particular specimen geometry which has similar dimensions to typical components of interest. The design of an appropriately scaled torsion tester is then presented followed by measurement test results for various bonding conditions.

\section{TEST DESCRIPTION}

\section{Technique}

A common requirement in MEMS related or planar based testing is to be able to gather data locally across a substrate area rather than measure averaged properties to generate confidence in the uniformity and applicability of the measurand to actual devices. For this reason, a distributed array of torsion specimens has been implemented. The chosen specimen 
geometry is a scalloped ring shape with $3 \mathrm{~mm}$ outer diameter as shown in the array of Fig. 4 . Deep $x$-ray lithography based processing provides the ability to accurately fabricate this scalloped ring structure to several hundred micron thickness making it feasible to mate a complementary circular pin array coupler. The coupler has also been realized with the aid of DXRL processing by creating a $650 \mu \mathrm{m}$ thick nickel fixture with six holes located in a hexagonal

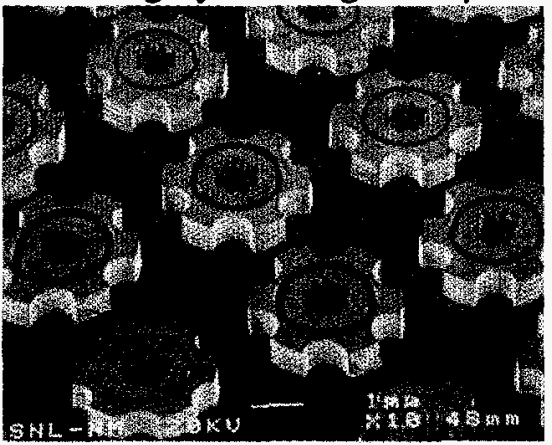

Fig. 4 SEM photo of array of nickel torsion test specimens diffusion bonded to a nickel substrate. The inner ring was provided to allow press-fitting of an alignment pin if required for assistance with alignment during mating with the tester. pattern on a $3 \mathrm{~mm}$ diameter bolt circle which accommodate the press-fitting of six lengths of gauge pins with precision lapped and polished ends. The gauge pins are 0.0320 " in diameter and are made of hardened tool steel. In order to maintain a shear stress which is nearly constant, a thin ring is desired while at the same time needs to be thick enough to resist buckling. An array of scalloped rings with ring widths between 100 and $300 \mu \mathrm{m}$ was used to identify any measurement variation due to ring width.

\section{$\underline{\text { Tester Design }}$}

A method is needed to conveniently apply a calibrated torsional load from the coupler to scalloped ring specimens decorated in an array across a substrate while gathering data in real time. Photographs of the resulting testing system are shown in Fig. 5. The substrate with diffusion bonded torsion test specimen rings is bonded to a plate which is bolted onto a platen that moves on ball slides in the $\mathrm{x}-\mathrm{y}$ direction and is spring loaded in the $\mathrm{z}$-direction. The spring force of the platen in the $\mathrm{z}$-direction holds the specimen in position within the pins while the torque is applied. The $\mathrm{x}$ and $\mathrm{y}$ slides are locked into position with thumbscrews before testing. The mating coupler is bonded into the pin housing with high strength epoxy. The pin housing rotates on precision bearings and is fixed in the lever arm which applies torque and shears the ring from the substrate. A Newport micro-actuator (DC screw drive) with $7 \mathrm{~mm}$ travel displaces a load cell mounted on a ball slide. The slide mounted load cell then pushes on the lever arm at a point $50.8 \mathrm{~mm}$ from the center of rotation. This moment arm length changes by less than $0.5 \%$ over the $7^{\circ}$ of total rotation of the lever. The angle of rotation is also closely approximated based on the displacement of a spring loaded LVDT at the end of the lever arm. The spring maintains a constant preload against the actuator which ensures that the lever always returns to the same position between tests. If the scalloped ring jams and remains suspended in the pins a spring-loaded pin located in the lever pivot shaft is manually activated to eject the specimen. A Validyne signal conditioner provides the calibrated load and displacment signals. Data are collected using a PC running LABTECH Notebook. With the specimen engaged firmly in the pins, the acquisition program is started and the actuator remote control is activated. The test is graphically represented in real time on the computer screen. A sequence of pin engagement and testing is shown in Fig. 6.

\section{Sample Preparation}

All nickel plating was performed in a nickel sulfamate bath at $50^{\circ} \mathrm{C}$ with a current density of $50 \mathrm{~mA} / \mathrm{cm}^{2}$. Prior to bonding and subsequent to lapping and removal of PMMA, both nickel

surfaces are cleaned with an oxygen plasma followed by an ammonium hydroxide treatment to 
remove the nickel oxide [7]. The substrates are immediately placed in a vacuum hot press which is evacuated to $10^{-6}$ Torr and backfilled with argon prior to heating and pressing. The hot press is equipped with 3"diameter carbon rods and is capable of applying a 50 Ton load at $1100^{\circ} \mathrm{C}$. Graphoil sheets are placed between the carbon rods and the substrates to help disperse the load evenly across the back of the substrates.

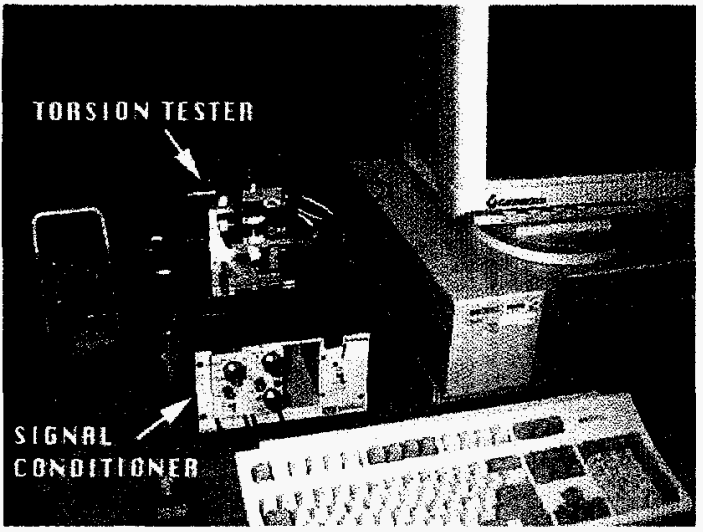

(a)

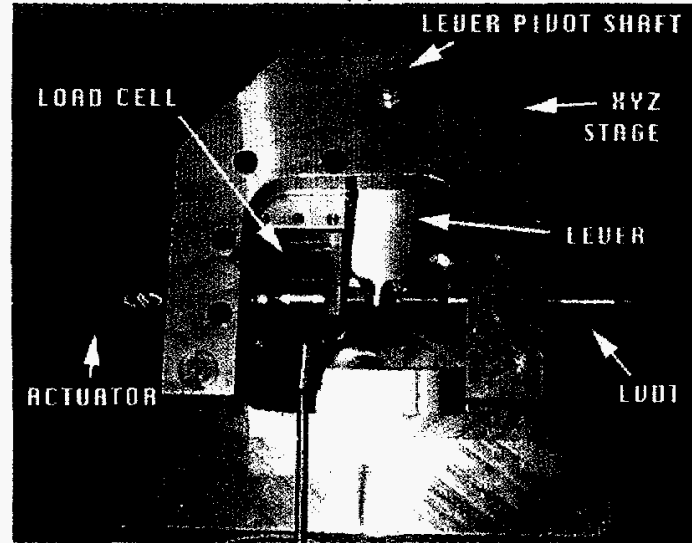

(c)

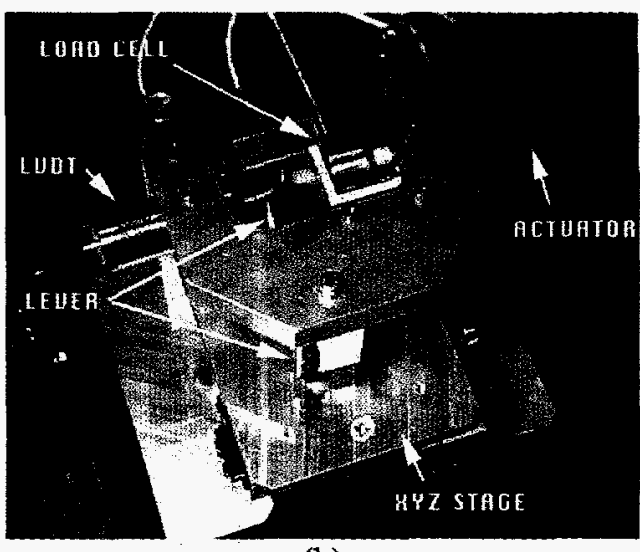

(b)

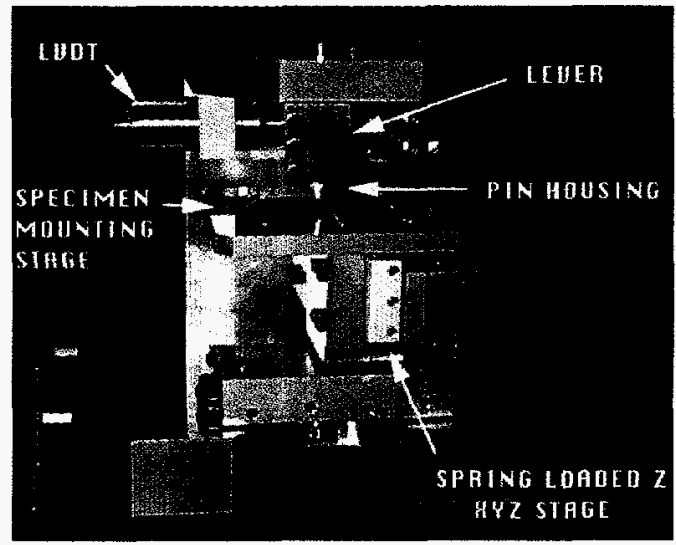

(d)

Fig. 5 (a) Photograph of the entire measurement system including a PC to take data and provide real time display of the load-displacement curve. (b) Perspective view of the tester showing the actuator drive screw that contacts the load cell which is free to move against the lever. The LVDT measures the lever arm displacment at a point directly opposite the load cell nylon lever contact button. Displacement measurement in this position, directly against the lever arm, eliminates errors from load cell compliance. (c) Top view of tester showing that the path of the actuator/load cell is a straight line perpendicular to the center position of the lever arm total travel and tangential to the moment arm circle. (d) Front view showing the specimen holding platen attached to 4 ball slides.

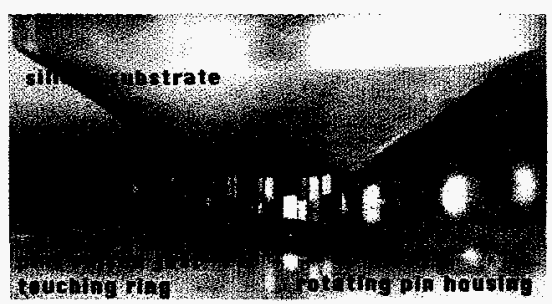

(a)

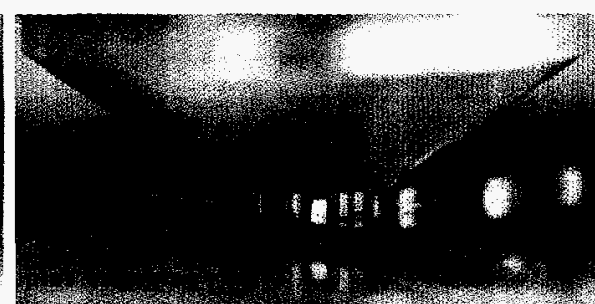

(b)

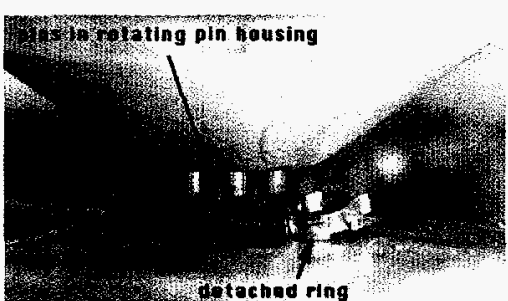

(c)

Fig. 6 Close-up photographs showing alignment (a) pin engagement with the specimen (b) and completed test with detached ring (c).

\section{RESULTS}

A typical torque-angle torsion measurement data set is shown in Fig. 7(a). This sample was bonded at $450^{\circ} \mathrm{C}$ with $7 \mathrm{ksi}$ bond pressure. The resulting shear strength of the bond averages $130 \mathrm{MPa}$ amongst the various specimens which is slightly less than half the yield 
strength of the as-deposited nickel material [8]. For most micromechanical applications this bond strength is sufficient.

Initial diffusion bond experiments prior to diffusion bond testing suggested exceptional electroplated $\mathrm{Ni}-\mathrm{Ni}$ bond strengths at temperatures well less than half the absolute melting temperature of nickel $\left(690^{\circ} \mathrm{C}\right)$. A common practice, however, is to require at least two thirds the absolute melting point temperature to achieve a good bond. One possible cause for this was suspected to be assistance from grain growth of the very fine grain electrodeposit to enhance a coalescence at the diffusion bond interface. If this was the case, subsequent bonding may be compromised by previous heat treatments. In order to identify this potential difficulty, fully annealed nickel base substrates were incorporated in the testing. One result is shown in Fig. 7 (b) which used a bonding temperature of $550^{\circ} \mathrm{C}$ at $10 \mathrm{ksi}$ bond pressure. The test was stopped at a maximum applied shear stress of over $600 \mathrm{MPa}$ which at that point yielded the ring specimen. Nearly identical bond strengths to as-electroplated nickel were found on annealed material at lower temperatures as well. What appears to be most important in the bonding process is the cleanliness of the nickel.

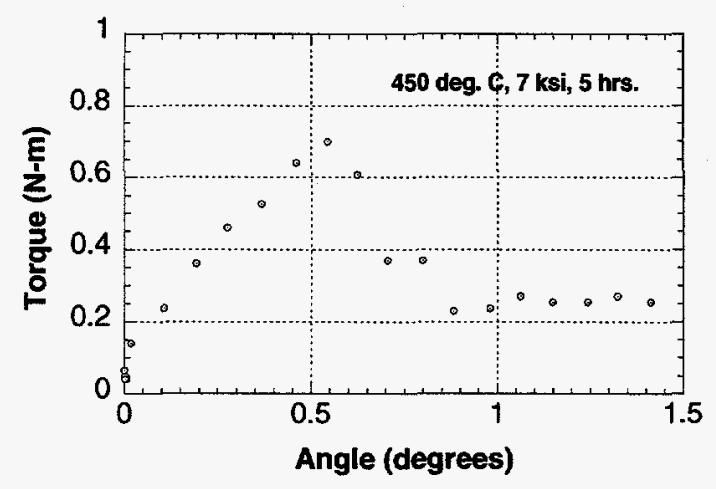

(a)

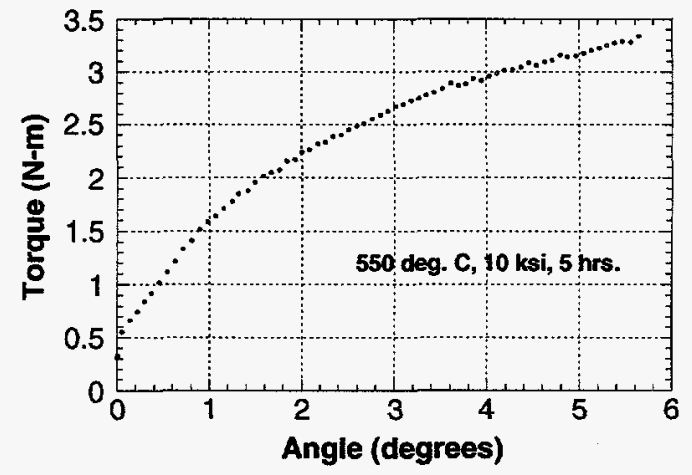

(b)

Fig. 7 Torsion test curves for two different diffusion bond conditions.

An additional benefit of this testing is the ability to measure adhesion of any LIGA electroformed material to any substrate and thus also test adhesion of plating base material to substrates. An example of this measurement is shown in Fig. 8.

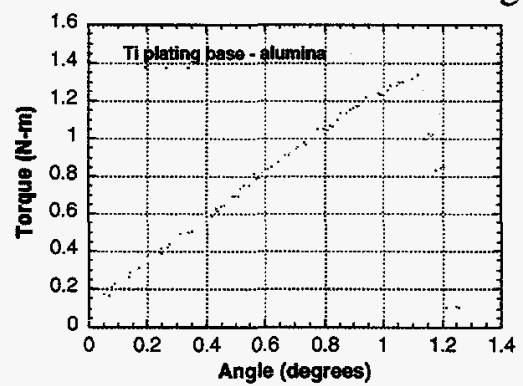

Fig. 8 Adhesion measurement of titanium plating base to an alumina substrate accomplished via the ring specimen torsion tests.

To additionally verify the bond integrity in both as-electroplated and annealed conditions, the metallurgy of the diffusion bond interface was examined. These results are shown in Fig. 9 and indicate in both cases grains spanning the interface.

\section{CONCLUSIONS}

The LIGA torsion testing system is found to provide convenient in-process diffusion bond strength measurements as well as adhesion measurements for a variety of interfaces. The technique provides the opportunity to optimize the process for a given required bond strength. 


\section{ACKNOWLEDGEMENTS}

The author would like to acknowledge L. Brown and F. Perez for performing the initial diffusion bonding experiments. Thanks are due to A. Kilgo and B. Ritchey for providing metallurgy and SEM expertise. The assistance of $\mathrm{C}$. Newton with operation of the vacuum hot press is also gratefully acknowledged. This work was performed at Sandia National Laboratories, a multi-program laboratory operated by the Sandia Corporation, a Lockheed Martin Company, for the U.S. Department of Energy under contract DE-AC04-94AL85000.
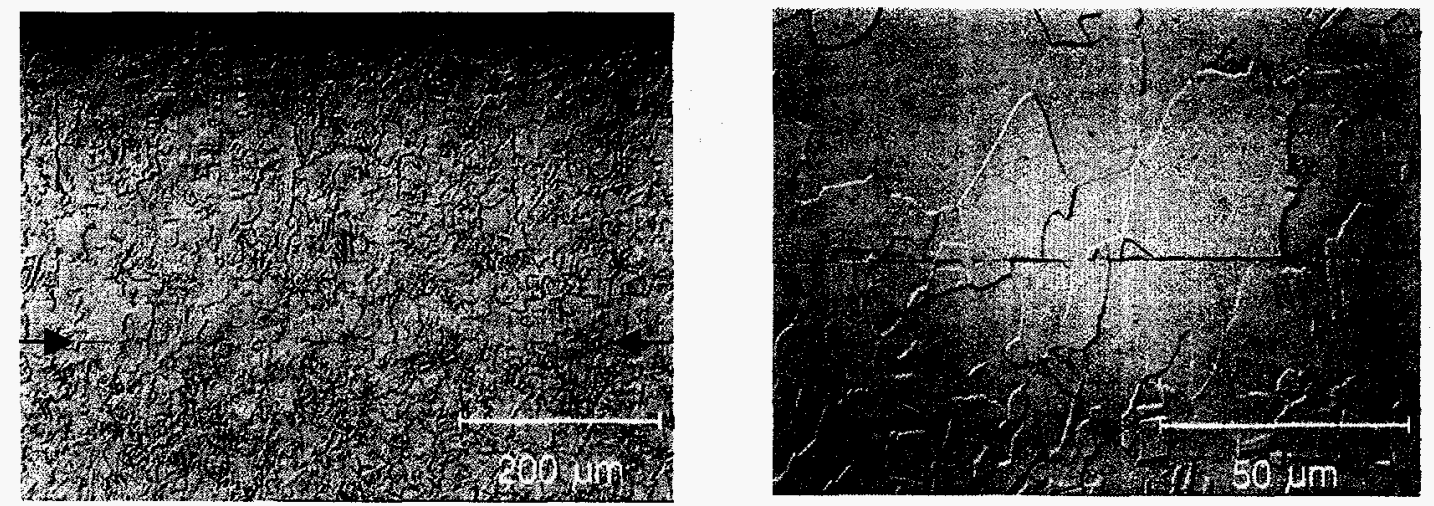

(a)
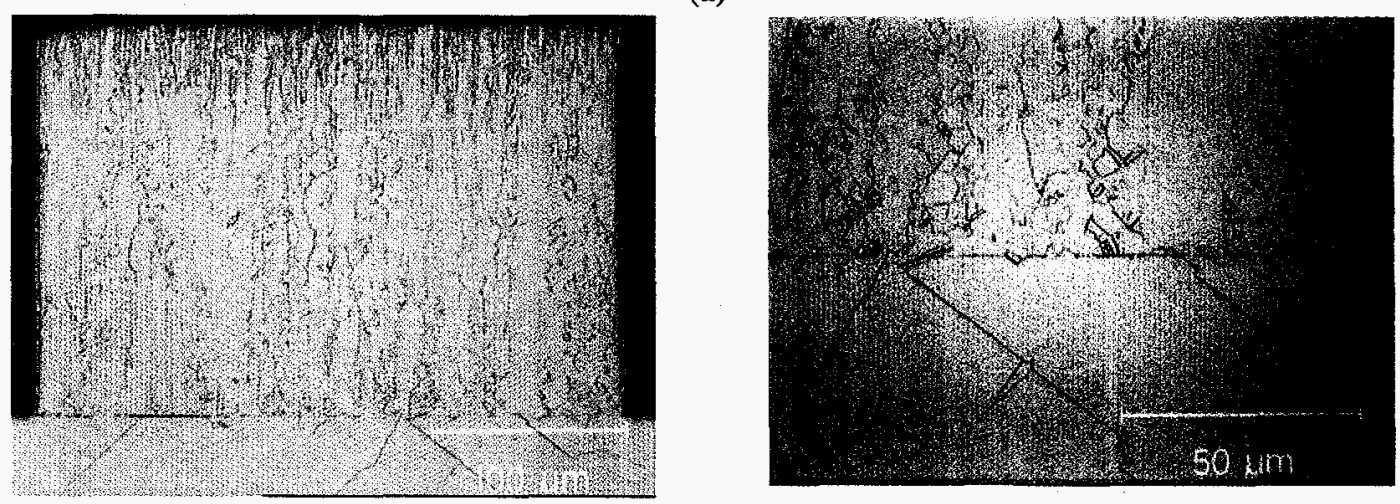

(b)

Fig. 9 Metallurgy results for (a) as-electroplated $\mathrm{Ni}$ to as-electroplated $\mathrm{Ni}\left(550^{\circ} \mathrm{C}, 10 \mathrm{ksi}\right)$ (b) as-electroplated $\mathrm{Ni}$ to annealed nickel $\left(550^{\circ} \mathrm{C}, 10 \mathrm{ksi}\right)$

\section{REFERENCES}

1. E.H. Klaassen, K. Petersen, J.M. Noworolski, J. Logan, N.I. Maluf, J. Brown, C. Storment, W. McCulley, and G.T.A. Kovacs, in Tech. Digest Transducers '95, Stockholm, pp. 556-559, 1995.

2. H. Guckel, Proc. of the IEEE, 86 (8), 1586-1593, (1998).

3. E.W. Becker, W. Ehrfeld, P. Hagman, A. Maner, and D. Münchmeyer, Microelectronic Eng., 4, 35 $56,(1986)$.

4. T.R. Christenson, H. Guckel, in Proc. of SPIE Micromachining and Microfabrication Process Technology, 2639, 134-145, (1995).

5. H. Guckel, P.S. Mangat, H. Emmerich, S. Massoud-Ansari, J. Klein, T. Earles, J.D. Zook, T. Ohnstein, E.D. Johnson, D.P. Siddons, T.R. Christenson, in Tech. Digest 1996 Solid-State Sensor and Actuator Workshop, Hilton head, SC, 60-63, (1996).

6. T.R. Christenson, D.T. Schmale, to be published in Proc. of MEMS '99, Orlando, FL, (1999).

7. P. Walker and W.H. Tarn, Eds., Handbook of Metal Etchants, (CRC Press, Boca Raton, FL, 1991), p. 874 .

8. T.R. Christenson, T.E. Buchheit, D.T. Schmale, and R.J. Bourcier, in Microelectromechanical Structures for Materials Research, (Mater. Res. Proc., 518, San Francisco, CA, 1998) to be pub. 